\title{
Thermovision monitoring of the tuberculin reaction with children
}

\author{
by A. Jung ${ }^{1}$, J. Zuber ${ }^{2}$, P. Sacha ${ }^{3}$, J. Lukasiewicz ${ }^{3}$
}

${ }^{1}$ Pediatric and Nephrology Department of Central Clinical Hospital, Military School of Medicine, Warsaw, Poland; ${ }^{2}$ Department of Infectious Diseases and Allergology of Central Clinical Hospital, Military School of Medicine, Warsaw, Poland; ${ }^{3}$ Thermovision Laboratory, Air Force Institute of Technology, Warsaw, Poland.

\begin{abstract}
Tuberculin reaction is still one of the basic criteria of diagnosing tuberculosis of children. This test should be performed by trained personnel. Doubtful reactions should be estimated by a doctor. Nevertheless, interpretation of results is often difficult. A test reading consists in estimation of a transversal diameter of infiltration. The character of a reaction is also taken into account (exudation reaction in spite of its size always testifies to an infection). A period of time which has passed since the previous BCG vaccination should be known to differentiate infectious and vaccination reactions. Visual examination of test results is not fully objective in spite of fixed criteria for positive tests. For this reason some other and more precise ways of taking measurements are searched. In case of tuberculin tests such studies are well-founded because recognition of a test as a positive one initiates a long and expensive process of diagnosing of potential tuberculosis infection.

The aim of the presented work was to compare results of tuberculin tests obtained with visual and thermovision (THV) methods.
\end{abstract}

\section{Material and method}

Tests were carried out with 33 children aged 4 to 14 given treatment in the Clinic of Pediatrics and Children Nephrology of Central Clinical Hospital of Military Academy of Medicine and turning up for control examinations. Tuberculin tests were applied according to general rules. Intradermic injections of $0.1 \mathrm{ml}$ of tuberculin RT 23, i.e. 2 international units, were applied wearly in the middle of the left forearm (in the area of flexors and extensors passing by). The test readings were taken 72 hours after injections. A visual examination method consisted in measuring transversal diameters of infiltration and erythema.

Thermovision examinations were performed using a thermographic system produced by AGEMA Infrared Systems $A B$ (Sweden) for remote detection and recording of infra-red radiation. The system used consists of:

- a thermovision scanner 900 SW/TE (working in the band of 2 to $5.4 \mu \mathrm{m}$ ) cooled thermoelectrically, with $20^{\circ}$ objective without additional filters,

- a computer controlled system with digital recording and real-time image analysis capabilities,

The THV tests were carried out under the following constant conditions: environment temperature: of $24-26^{\circ} \mathrm{C}$, relative humidity of air: $48-50 \%$, distance from the area under examination: $75 \mathrm{~cm}$. With the THV method the temperature gradient between the place of application of the MtxRT23 reaction and surrounding skin was measured.

\section{Results and discussion}

Four groups of the examined children were distinguished depending on the results of the tuberculin tests.

I group - 8 children - positive results of the tests according to criteria of visual estimation.

II group - 8 children - papule diameters of less than $6 \mathrm{~mm}$; however, distinct infiltration and/or erythemas. 
III group - 5 children - erythemas and papules not discovered with the visual method; on the other hand, the THV examination shows elevated temperature gradient which may correspond to an erythema or a papule.

IV group - 12 children - negative test results for both the visual and the thermovision methods.

For all examined groups diameters of erythemas and papules have been calculated for both the visual and the THV methods (see Table1). These calculations have been made by means of the computer software with the effect of irregular shapes of skin-reaction areas on diameter values taken into account. All readings were taken 72 hours after test application.

The comparison of both the methods of tuberculin test reading shows that reading values gained with the THV method have been higher than those resulting from visual examination (see figure 2). It may evidence higher sensitivity of the thermovision method based on a recording of local infra-red radiation which exhibits higher intensity in the area of molecular infiltration of a papule and extended vascular microplacenta of an erythema. This difference is most distinct in the III group of patients, in case of which visual examination has not revealed any readings. On the other hand, the THV examination shows two regions of elevated temperature that have been recorded and may correspond to infiltration and erythema (see figure 2). It is quite possible that these differences do not mean any revolution in criteria of positive reaction to tuberculin test; nevertheless, they clearly show that the traditional method is imperfect. Thermovision measurements of the temperature gradient and of the area of skinreaction in the test spot exhibit much higher accuracy. The area of skin reaction is measured according to a chosen isotherm. The exudation reaction is visualised with the THV method as a so-called temperature "crater" (see figure 1). A similar phenomenon that substantially disturbs the correlation between visual and thermovision examination results has also been observed for reactions to point skin tests. Some authors maintain that in case of the tuberculin test the intensity of reaction may be an essential element often imperceptible in visual examination. This statement has been illustrated with results in the II group (see figure. 2.). The sizes of skin-reaction areas evaluated with the visual method are close to limit values and do not allow these results to be qualified as positive reactions. Significant differences between areas of elevated temperature may be decisive in diagnostics of doubtful positive reactions. It seems that the application of techniques that improve the accuracy of test reading (especially of those as important to basic diagnostics as the tuberculin test) may verify - to some extent the already used traditional methods.

\section{REFERENCES}

[1] ABBOT (M.C.), SWANSON (B.J.), HARRISON (D.K), WILSON (S.B.) - Dynamic thermographic imaging for estimation of regional perfusion in the tuberculin reaction in healthy adults. Journal of Immunological Methods. 1993; 162:97.

[2] BRANEMARK (P.J.), HERSTLE (K.), MAGNUSSON (D.), MOBACKEN (H.) Thermographics evaluation of patch test and tuberculin reactions. Acta Derm. Venerol. 1969; 48:385.

[3] JUNG (A.), ZUBER (J.), KALICKI (B.), SACHA (P.), LUKASIEWICZ (J.) - Ocena termowizyjna odczynow tuberkulinowych u dzieci. Postepy w Pneumonologii i Alergologii Dzieciecej. Warszawa 1996; 73:86.

[4] De WECK (A. L.) - Perspectives in allergy diagnosis. Int. Arch. Allergy Immunol. 1992; 99:252. 


\section{http://dx.doi.org/10.21611/qirt.1996.056}

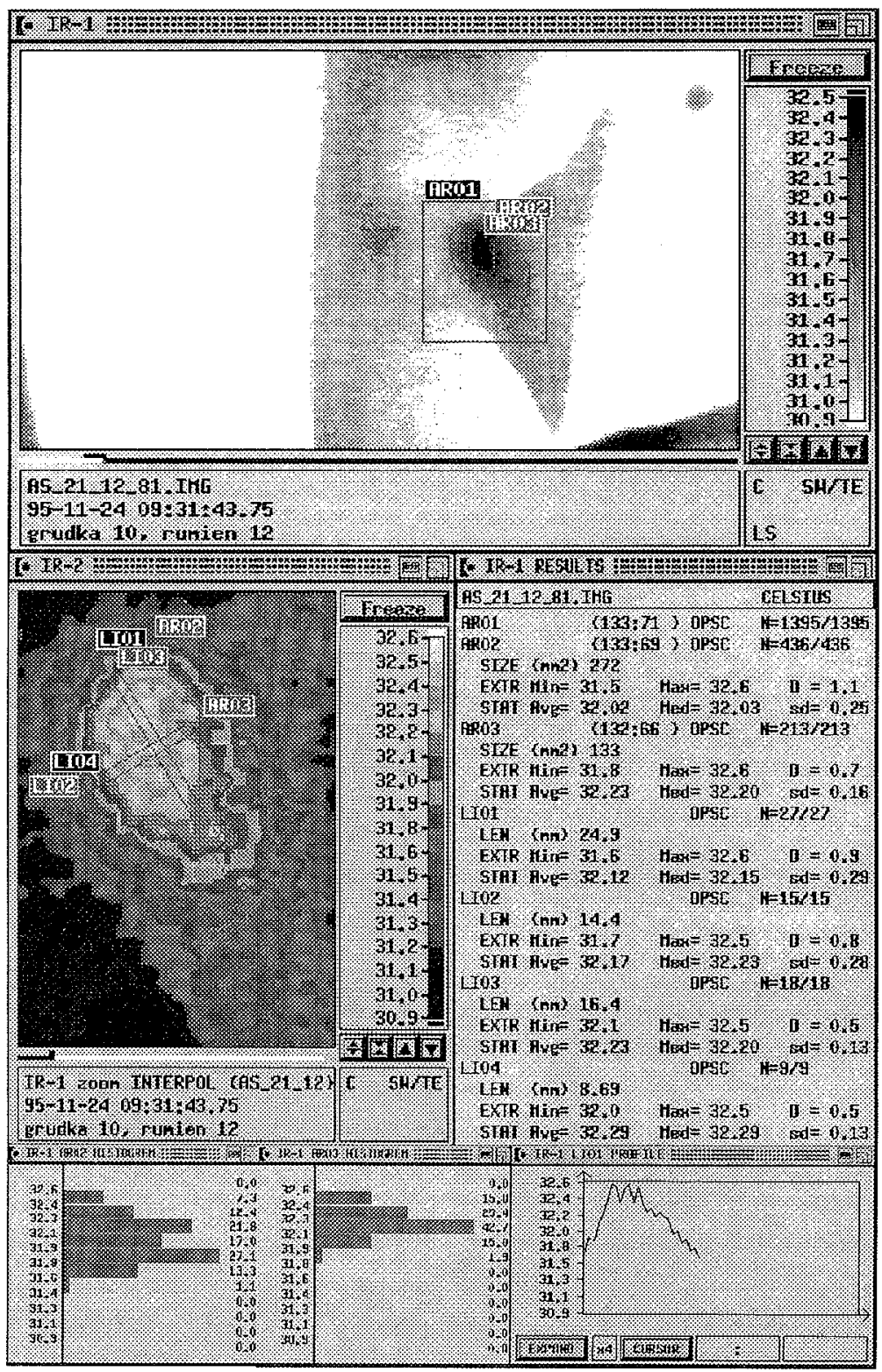

Fig. 1. An example of thermovision analysis of papule and erythema parameters of tuberculin reaction. 
Table1. Diameters of erythemas and papules evaluated with visual and thermovision methods

\begin{tabular}{|c|c|c|c|c|c|c|}
\hline \multirow{2}{*}{ GROUP } & \multirow{2}{*}{$\begin{array}{c}\text { NUMBER } \\
\text { OF } \\
\text { PATIENTS }\end{array}$} & \multicolumn{2}{|c|}{ Diameter (mm) } & \multicolumn{2}{|c|}{ Area (mm2) } & \multirow{2}{*}{ Methods } \\
\cline { 3 - 6 } I & \multirow{2}{*}{8} & 11.4 & 13.1 & 101.5 & 135.2 & Visual \\
\cline { 3 - 6 } & & 12.1 & 14.5 & 124.8 & 163.9 & THV \\
\hline \multirow{2}{*}{ II } & \multirow{2}{*}{8} & 2.5 & 4.9 & 4.9 & 18.7 & Visual \\
\cline { 3 - 6 } & & 2.6 & 5.2 & 5.6 & 23.2 & THV \\
\hline \multirow{2}{*}{ III } & \multirow{2}{*}{5} & 0.0 & 0.0 & 0.0 & 0.0 & Visual \\
\cline { 3 - 7 } & & 0.6 & 2.5 & 2.8 & 8.1 & THV \\
\hline \multirow{2}{*}{ IV } & \multirow{2}{*}{12} & 0.0 & 0.0 & 0.0 & 0.0 & Visual \\
\cline { 3 - 6 } & & 0.0 & 0.0 & 0.0 & 0.0 & THV \\
\hline
\end{tabular}
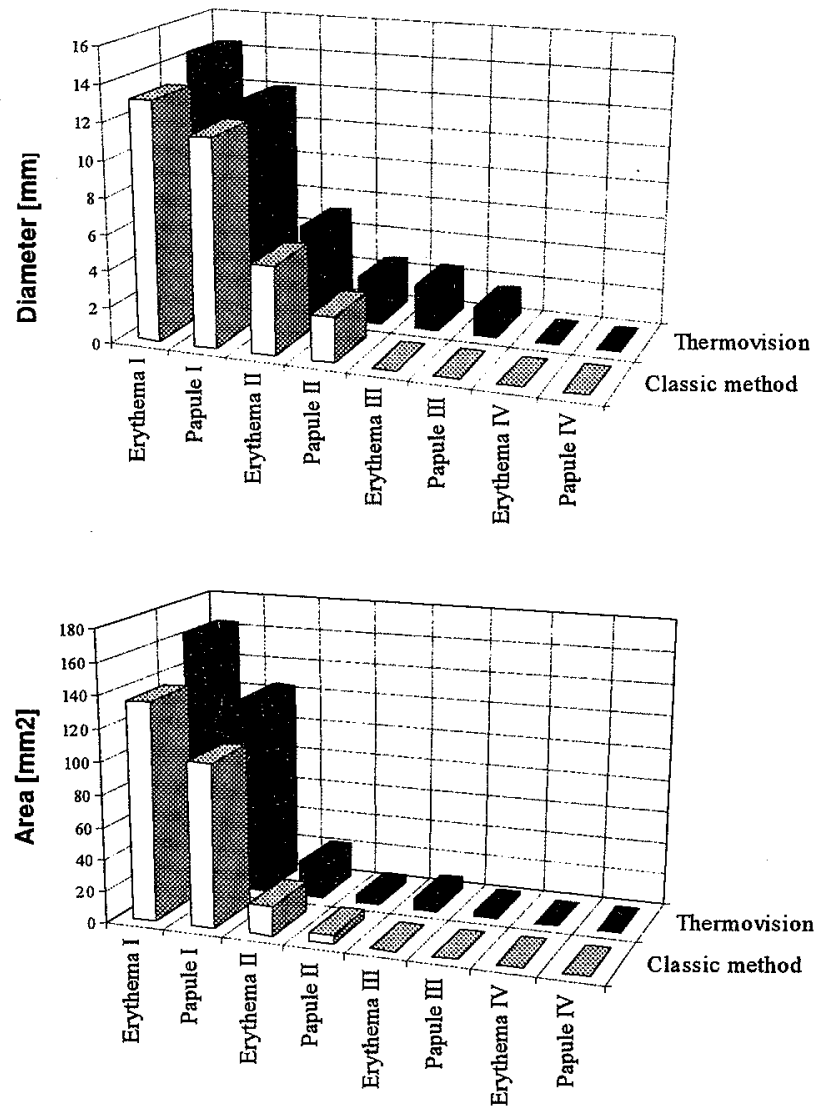

Fig. 2. Diameters and areas of erythemas and papuies 